\title{
La leyenda aborigen en la lírica de Juan M. Gutiérrez y Adolfo Berro
}

Palabras clave: Adolfo Berro, Juan María Gutiérrez, leyenda aborigen, etnografía, literatura.

\section{Introducción}

La atención de los letrados americanos del XIX sobre la herencia de la cultura aborigen para la construcción identitaria es un tema que ha sido estudiado desde diversos ángulos. En el contexto del Río de la Plata, el lugar del aborigen en el imaginario es particular por las características del poblamiento y distribución de los grupos nativos en el territorio, y por las campañas de exterminio de estos colectivos y las de inmigración europea que configuraron el blanqueamiento poblacional (Quijada, 2001: 57-92). Así y todo, también se han estudiado otros usos semánticos y simbólicos de lo aborigen, desde las propuestas de institución del incario durante la declaración de la independencia (Díaz-Caballero, 2005) hasta las más singulares y conocidas producciones literarias, como el Tabaré (1888) de José Zorrilla de San Martín. En el contexto general latinoamericano, novelas, poemas y ensayos que reivindican las posibilidades simbólicas del aborigen en Argentina y la Banda Oriental serían muestras de una tendencia de idealización con tradición en los estudios literarios (Meléndez, 1961; González Stephan/Lasarte, 1995). Pero dentro de los sistemas de representación locales, son cuestiones aisladas en apariencia y dignas de revisar.

Mientras que el pensamiento de Domingo F. Sarmiento, primero y, más tarde, el de José E. Rodó, consideran un tema prescindible la cuestión aborigen en la cultura rioplatense, Juan María Gutiérrez, por ejemplo, despliega a lo largo 
de su producción un interés significativo por los habitantes originarios del territorio y su cultura. En primer lugar, este interés por las notas distintivas de la voz, la lengua y la identidad americana aparecen en su discurso en el salón de Marcos Sastre y en su arraigada postura antihispánica (Ortiz, 2007) y, más tarde, en su trabajo América poética (1846) y sobre todo, en «De la poesía y la elocuencia de las tribus de América» y los poemas que se analizarán en este trabajo.

Para Salto (2010) y Pas (2012), la atención filológica sobre las lenguas aborígenes surge en Gutiérrez por la influencia de los trabajos y contactos con los letrados chilenos José Victorino Lastarria y Miguel de Amunátegui. Para Salto (2010), por ejemplo, la actitud de Gutiérrez era crítica con el tratamiento de las lenguas aborígenes por parte de las gramáticas de la conquista, y con la poetización de los mapuches hecha por Ercilla y encumbrada por Bello (2010: 3). Las fuentes leídas e integradas por Gutiérrez en su estudio filológico (los relatos de etnólogos y viajeros, y textos redescubiertos durante sus viajes por Chile, Perú y Ecuador) y el enfoque que le imprime a su ensayo tiene un punto de vista diferente en comparación con el de sus poemas de la década del 30.

\section{Juan María Gutiérrez: cultura aborigen y documentos coloniales}

Gutiérrez es, como Vicente Fidel López, uno de los primeros argentinos que se interesaron por el pasado colonial del territorio. La labor recopiladora del napolitano Pedro de Ángelis, y su Colección de Obras y Documentos relativos a la bistoria antigua y moderna de las provincias del Río de la Plata, comenzada en 1836, así como los trabajos posteriores del periódico El Comercio del Plata, fueron aportes editoriales e historiográficos que les permitieron a los letrados rioplatenses tener un contacto directo con los testimonios sobre la conquista y colonización de su territorio. Además, en consonancia con el progresismo histórico y el romanticismo europeo, los textos del período colonial se convirtieron en fuentes para la recreación de un pasado necesario para construir el acervo espiritual e identitario.

Gutiérrez fue el responsable del redescubrimiento y de la edición del Arauco domado de Pedro de Oña (Rodó, 1965: 271), que también incluyó en el ensayo «Estudios biográficos y críticos de poetas sudamericanos anteriores al siglo XIX». Por otro lado, en el ensayo «De la poesía y la elocuencia de las tribus de América» hace un acercamiento muy novedoso sobre la mitología guaraní, 
y sobre la lengua de este pueblo y la de los araucanos o mapuches. Gutiérrez valora en este trabajo dos cosas: la calidad de las lenguas aborígenes y sus posibilidades expresivas. De éste se desprende que el estudio de las lenguas nativas facilitaría «encontrar los elementos ancestrales que permitieran anclar una literatura original, que en los términos de su argumentación implicaba independiente» (Salto, 2010: 2) y que de ellas surgía un valor que le otorgaría a los americanos «un modelo retórico virtual y, en gran medida, utópico» (Ibíd.). Este estudio filológico refleja, por un lado, la revalorización del patrimonio prehispánico. Si bien es una aproximación bibliográfica, reviste una importancia central. En primer lugar, porque lo que muestra es un diálogo intelectual con varios autores -seguramente, recomendado por sus amigos chilenos- por ejemplo, con Alcides D’Orbigny, y en segundo lugar, porque establece su punto de vista crítico y filológico al intentar desentrañar las etimologías y los rudimentos de estos idiomas, ayudado por el Tesoro, el Vocabulario y la Gramática del jesuita Antonio Ruiz (Gutiérrez, 2006: 255-308).

Además de este aporte, Gutiérrez trabaja en una tesis revalorizadora. Dialogando con los cronistas y con la perspectiva tradicional sobre las tribus de la región, plantea que los guaraníes y los araucanos tuvieron un desarrollo superior al estimado, que no eran pueblos tan guerreros ni antropófagos como se decía, y que esto se notaba especialmente en la belleza de su lengua y en la complejidad de su mitología.

En el apartado sobre la mitología del pueblo guaraní, Gutiérrez glosa L'bomme américain de D'Orbigny y da cuenta de un principio central de la antropología estructural del siglo XX y base de la teoría de los arquetipos de la mitocrítica actual:

Pero nuestro propósito no es considerar a los indígenas bajo el aspecto de sus costumbres, sino como seres capaces de funciones intelectuales que honran a nuestra especie. Entre estas facultades, la de crear con la fantasía y animar con ficciones la obra de la naturaleza, atribuyéndola calidades y destinos puramente ideales, es la que más seduce y más hondo rastro deja en la historia de los pueblos que han desaparecido [...] El recuerdo de esta nación culta y poética por excelencia, se nos presenta, casi sin quererlo, delante de las creaciones fabulosas de los habitantes primitivos de América, dándonos motivo esta rara asociación de entidades tan remotas, para admirar la analogía que existe en las concepciones humanas, 
por muy diversas que parezcan las civilizaciones, las sociedades y los climas (1940: 87-88).

En suma, Gutiérrez consideraba que las leyendas de estas naciones tenían unidades narrativas y núcleos míticos similares a los de la cultura occidental. Y estas potencialidades argumentativas ya se aprecian en algunas de sus composiciones poéticas de su autoría y en la de algunos escritores orientales.

\section{El poema de Centenera y la lira rioplatense}

La relectura del poema Argentina y conquista del Río de la Plata (1602), de Martín del Barco Centenera, tiene una significativa resonancia histórica y literaria durante el siglo XIX. Además de proveer de toponimia de un país (Rosenblat, 1964), es uno de los documentos coloniales más citados y reelaborados en la menguada producción literaria de la región entre las décadas del 30 y 50, y está, para Gordon Brothertson (2010), en la génesis no declarada del poema épico de Zorrilla de San Martín, Tabaré.

A partir de esta tesis, analizaré el proceso de poiesis de este hipotexto en dos poemas de Juan María Gutiérrez y en uno de Alfredo Berro. En concreto, me centraré en el trasvase y transformación de las leyendas aborígenes de los textos coloniales en el género lírico de estos dos románticos rioplatenses. Si bien estos poemas deben ser considerados más como ejercicios de primeras letras que como obras cabales, me parece interesante ver cómo se integran las leyendas en el imaginario regional.

\section{1 «Caicobé»}

Esta composición, que aparece reunida en la edición de sus poesías completas, tiene como subtítulo el sintagma «leyenda guaraní». Está dedicado al doctor Florencio Varela e incluye dos epígrafes que cuentan de la fuente y la motivación temática de la leyenda. La fuente, por supuesto, la Argentina de Centenera. Gutiérrez elije de entre sus asuntos una pequeña alusión a la planta sensitiva, también llamada caicobé, para explayar una leyenda que el arcediano no desarrolla. La fuente se concentra en estos versos: «Un árbol hay pequeño de la tierra / Que tiene rama y hoja menudita: / En tocando la hoja ella se cierra, / Y en el puno se pone muy marchita» (Centenera, 1912: 17r). El segundo epígrafe, pues, consiste en tres versos originales pertenecientes a Jean-Antoine Roucher, poeta francés antirrevolucionario. El fragmento poético refiere a una soledad rodeada por el reino vegetal, al pudor femenino franqueado y la 
muerte o el final de su naturaleza como consecuencia, alusiones que encuadran con la historia desarrollada en el poema ${ }^{1}$.

Gutiérrez toma el término guaraní caicobé para denominar al arbusto mimosa sensitiva, una especie vegetal americana descrita por Linneo e incluida en su Species Plantorum, cuyo origen es el Brasil. La llama por su nombre aborigen y va a establecer una metáfora directa para elaborar la leyenda basada en las características de la planta y en su etimología. Según la referencia léxica que el mismo autor hace en «Algunas observaciones sobre las lenguas guaraní y araucanas», comenta que la partícula cai significa mono, pero también la acción de estos animales de taparse la cara y agrega «lo han tomado por avergonzarse» (Gutiérrez, 1943: 143). Es decir, la sensitiva es una especie que se avergüenza, que se cierra al contacto o percepción de seres vivos cercanos. Es interesante cómo Gutiérrez insinúa esta explicación filológica, a la manera de San Isidoro de Sevilla y sus etimologías, y no en la de su hipotexto, ya que Centenera establece una para el nombre indígena:«Caycobe se 1lama, y es tenida / por viva yerba y nómbranla de vida» (Centenera, 1912: 17r). Y en nota: «La yerbaviva llamada Caycobé, 'ca' significa 'yerba' y 'cobé, 'que vive'» (nota 17r.), definición seguida por Juan Zorrilla de San Martín en su glosario del Tabaré (1943: 247)². Gutiérrez no sigue, así, la etimología. Trabaja en base a analogías para recrear el posible origen mitológico de esta planta tan particular.

Por su parte, el arcediano hace referencia a la planta sensitiva como parte de una descripción fabulosa propia de la tradición discursiva de los documentos de la conquista. La sensibilidad de una planta, así como las costumbres de los papagayos y la habilidad de un oso hormiguero para matar a un tigre (Centenera, 1912: 17v,18r) son relatados en el poema más como una tipificación del espacio americano que como fuente referencial. Desde esta ficcionalización de la experiencia, el poeta del siglo XIX elige el formato de una metamorfosis. La «indiana morena» aparece al comienzo en la figura de las huellas que se dejan en la arena. La alusión de esta sinécdoque ya nos prepara para el futuro etéreo de la mujer. Ella, a su vez, cubierta sólo de plumas, huye de dos hombres que la persiguen. En este escenario se mezclan el mundo referencial -los hombres son dos soldados españoles de la conquista- y el mundo mítico, ya

1 «A solas entre las flores, frente al hombre temeroso; / Sin duda ello te recuerda que mortal otra vez / Se desconoció la voz de tu joven pudor» (Gutiérrez, 1869: 113).

2 En consonancia con esta ficción etimológica, es curioso que el crítico argentino considerara al guaraní una lengua «verdaderamente muerta para nosotros, a pesar de que se habla en una porción considerable del territorio argentino» (Gutiérrez, 1943: 129-130). 
que la morena es esposa del sol, la divinidad, que «teme perder del seno / un joya misteriosa / talismán contra el veneno / de la sierpe dañosa» (Gutiérrez, 1869: 114). La alusión del temor a la pérdida, en el contexto de una persecución, nos ubica inmediatamente en una descripción sensual: se está hablando de un acoso sexual a una inocente. Las alusiones etéreas y carnales se alternan, como es habitual en la descripción romántica de los aborígenes - «parece una nube pintada» (Ibíd.) y «lleva las trenzas caídas» (Ibíd.); «el ajitado seno / ardiente como el verano / matador como el invierno» (1869: 115) - e insinúa el doble plano de acción de la historia. Por un lado, la india perseguida es por sí misma un objeto de seducción, una mujer atractiva, y por otro lado, es un ser inocente, esclava, porque se encuentra sobre la tierra rendida y atada como una gama (1869: 118).

En medio de esa impotencia en la persecución - una suerte de batalla en clave femenina- la mujer implora al dios Sol que, como esposa suya, se apiade de ella y la salve transformándola en un ser de la naturaleza: «Cámbiame en rayo de tu luz pintado / en mariposa que tu luz refleje, / en árbol por la brisa acariciado / o en tórtola amorosa que se queje». (1869: 117). Durante la plegaria, el sol se mantiene hierático y parece no responder. Los hombres avanzan: uno de ellos, hijo de Andalucía, de fuertes brazos y la amenaza con «una ancha espada que aterra» (1869: 119). Pero entonces se produce el milagro: la noche cae abruptamente, y el soldado, despavorido, «creyendo que Dios le ciega/para que en pecar no insista» (Ibíd.), se postra en tierra y no cumple su cometido. La ceguera del deseo se transforma en ceguera como castigo del Dios cristiano y del dios Sol de la india, ya que se retira y lo hace perder.

La interpretación moralista decimonónica es curiosa en un espacio de leyenda. Aquí se entrelaza el sistema de creencias cristiano y el pagano sin inconvenientes. En seguida, surge el árbol «nunca visto en el desierto» (1869: 120). Con desierto, por supuesto, el yo lírico asume la realidad pampeana. Y, a su vez, empalma dos momentos, el histórico - de la conquista- y el mítico, la creación de una planta. Caicobé, la india, se convierte en la árbol, un vegetal que guarda dentro un tesoro: «pero así que la mano / toca en sus hojas o el aliento humano / las hojas se enrojecen / y púdicas se cierran y estremecen» (Ibíd.). La derivación del movimiento de cierre de las hojas a la deducción axiológica del pudor, convierten a la leyenda no sólo en una representación cosmogónica -la creación de los seres de la naturaleza- sino también en una pauta de civilización.

Este poema confirma las apreciaciones de Gutiérrez sobre el grado de refinamiento de los pueblos guaraníes (por la inclusión de mitologías y 
pensamiento elaborado en ellos), y a él le suma la caracterización de una mujer pudorosa y el discurso de una conquista violenta que le dio la espalda a la sensibilidad divina. Hay, por supuesto, un código amatorio implícito dirigido a una lectora femenina a la que por primera vez se le pide identificarse con una mujer aborigen. En esto radica, por ejemplo, el carácter universal de ciertos principios e ideas, como sostiene Gutiérrez en sus ensayos sobre las etnias originarias.

Por supuesto que esta recreación de un mito guaraní se encuadra con la tendencia romántica de la recreación de un aborigen no real, con el rescate e idealización de antiguas razas perdidas que le dan un sustento cultural a los recientes proyectos nacionales. Y el tipo de leyenda se concentra en las historias de metamorfosis vegetales o almas externadas en plantas, cuya significación intracultural fue estudiada en la tradición occidental por varios autores desde Frazer (1981).

Otras leyendas de la tradición regional reelaboradas en el siglo XIX es la leyenda charrúa Cabarí (circa 1848), de Ramón de Santiago, que explica el nacimiento de la planta mburucuyá o pasionaria; La cbiriguana (1879) de Josefina Pelliza de Sagasta que convierte a sus amantes en emanación sobre el río. En el caso de Cabarí, también la metamorfosis se produce con el exterminio de la raza, pero durante el siglo XVIII. El tiempo debe ser, en el nivel de la representación, lo más alejado posible al siglo XIX.

\section{2 «Irupeya»}

Este otro poema de Gutiérrez también recrea una historia de persecución de una india. El marco de la historia es contada alrededor de un fogón. El personaje es Don Gonzalo de Alama, soldado de los primeros conquistadores del Río de la Plata. A su llegada a las playas, Irupeya, una india de quince años, se esconde entre las cañas. Aquí de nuevo se ensaya la etimología del nombre, ya que Irupeya se traduce como «torcaza» o «paloma», y es un mito del que no se declara fuente. De todos modos, es singular la similitud léxica entre Yrupeya e Irupé, la flor acuática, e incluso con Liropeya, la de la historia recreada por Berro que analizaremos a continuación. Yrupeya es descrita en versos octosílabos con todas las gracias propias de las bellezas exóticas idealizadas «flexible talle», «suave piel tostada» y se le agrega otra referencia prosoprográfica sensual: «El cabello en ondas lisas / le tapizaba la espalda / único velo tendido / sobre sus picantes gracias» (1869: 125). 
Luego de este esquema: relato enmarcado, presentación de la mujer, aparición del mancebo que se deslumbra con ella, irrumpe el ritmo y la secuencia otros soldados forajidos que la raptan: «Sobre los hombros robustos / que bárbaros la robaban / cual melancólica luna / que lucha con nubes pardas» (1869: 128). La india se desmaya, como era habitual en la mujer raptada, y la llevan al barco. Es decir, la imagen emblemática de la cautiva blanca de Echeverría es, en el poema de Gutiérrez, una india. El soldado de intenciones puras se rebela contra la barbarie de los otros, pero no tarda en llegar el castigo: «Una tribu toda entera / llegó clamando venganza» (1869: 131). Aquí es curioso cómo los indios que vienen en busca de su doncella no son las hordas salvajes de «La cautiva», sino desdichados hombres que quieren luchar con piedras y escamas contra las armas del español. Y además, el yo lírico apunta a que su única malla, su única protección era «la primitiva inocencia / que tanto vigor da al alma» (Ibíd).

\section{3 "Yandubayú y Liropeya»}

Los hipertextos del poema de Centenera producidos en el siglo XIX constituyen un ejemplo claro de existencia de un sistema literario común compuesto por autores, obras, revistas y círculos de una y otra banda del Río de la Plata. Especialmente esto se dio durante los años del exilio de varios miembros de la generación del 37 en Montevideo, entre 1838 y 1843. El período se podría extender también, como sostiene Zum Felde (1985: 111-158), hasta el final de la Guerra Grande (1851) y los comienzos del sitio de Montevideo.

En estos años, se produjo una amistad intelectual muy fructífera entre los exiliados (Juan M. Gutiérrez, Juan Cruz y Florencio Varela -los patronos del grupo y de los primeros en exilarse-, José Mármol, Miguel Cané, Esteban Echeverría, Luis Domínguez) y los orientales Adolfo Berro, Andrés Lamas y Juan Carlos Gómez, siempre cerca del respetado Francisco Acuña de Figueroa. Entonces se concretó, sin temores a borrones de identidad, una verdadera comunidad literaria, lejos de las inquietudes nacionalistas que aparecieron después. Las influencias de un prematuro y apenas definido romanticismo, sumado a la tradición clásica que seguía vigente en la forma lírica, por ejemplo, conformaron un movimiento cultural e ideológico, caldo de cultivo para muchos aportes posteriores.

A mi entender, el interés por la lectura del arcediano se traslada en el exilio a los autores orientales. Los porteños les hacen descubrir este texto como emblema originario sobre los acontecimientos históricos y los datos etnográficos 
de los pueblos originales de la Banda Oriental. En Adolfo Berro (joven poeta oriental que muere a los 22 años y que fue motivo y emblema de melancólicos homenajes), se plasman los incipientes intereses del romanticismo rioplatense y los ensayos de métrica.

En las historias de la literatura uruguaya siempre se ha mencionado a este joven autor, de breve trayectoria pero de gran representatividad (Roxlo, 1912; Bauzá, 1953; Rama, 1968; Real de Azúa, 1968). De a poco comienza a vincularse a Berro como un despunte del romanticismo, que luego tuvo su manifestación epigonal en Tabaré. Así, hay que entender la breve obra de Berro, los esbozos versificadores de Juan Carlos Gómez, la obra de Ramón de Santiago, Pedro Bermúdez y de Florencio Escardó, como muestras del acercamiento de la literatura a los temas protoculturales del territorio.

Berro recrea en su poema «Yandubayú y Liropeya (año de 1574)» (1840) la historia trágica de los amantes charrúas donde un soldado español, Carvallo, atenta contra la consumación de su relación. La historia, según se sabe hasta hoy, está tomada de la imaginación de Centenera, y bajo la inspiración de Glaura y Tegualda, la pareja de La Araucana; aunque, según Rodó, el romance charrùa es más interesante que su predecesor (Rodó, 1965: 315).

Lo cierto es que la historia de Centenera es muy sugerente e incluye, coherente con su discurso de sesgo crítico sobre la figura de los conquistadores, una versión de la historia desde el punto de vista del indígena. Así y todo, aunque se trate de una adanización del colectivo, la opción de contar los anhelos de un español sobre una indígena, a la inversa que los sucesos de Lucía Miranda acosada por Siripó y Mangoré, es una perspectiva sutil³. Aún lo es más cuando esta historia atraviesa, con algunas variaciones argumentales, la cultura uruguaya: la historia se reelabora en el drama El charrúa (1853) de Pedro Bermúdez, en la novela Abayubá (1873) de Florencio Escardó y en la ópera Liropeya (1912) del compositor León Ribeiro ${ }^{4}$.

El comienzo del poema de Berro es también una persecución pero, en este caso, hecha por soldado Carvallo a Yandubayú. Berro es quien respeta mejor el nombre original del indio de la historia de Centenera, Yanduballo, ya que las siguientes elaboraciones adjudicaron el nombre del amante de Liropeya el de Abayubá, otro personaje de Centenera. De todos modos, el punto de la

3 Me refiero al episodio que aparece en la Argentina manuscrita de Ruy Díaz de Guzmán de 1612. Sobre este tema, ver: Lojo (2007), Guérin (1990) y Ortiz Gambetta (2013, 181-189).

4 Existe también un drama en verso titulado Liropeya escrito por Mercedes Pujato Crespo (ن?-1954), autora santafecina, publicado en 1929. 
historia elegida por Berro es esa instancia, y el interés repentino de Carva1lo hacia Liropeya, cuando su prometido Yandubayú está a punto de matar al español.

En esta composición se evita el tema del abuso sexual de la india por parte del español, y la muerte del indio se da en manos de Carvallo por la codicia de éste hacia su salvadora. La joven muere en seguida por sus propias manos, con la espada conquistadora, y su cuerpo cae sobre el de su prometido «de castos amores» (Berro, 1864: 147). No hay venganza de los indios sobre Carvallo, como en las otras obras, no hay mancillamiento; sólo un acto injusto e inmerecido. La densidad lírica se encuentra en la trágica muerte de los dos amantes, y en consonancia con la lógica real de la conquista. Aunque, nuevamente, la enamorada charrúa se representa y mantiene los valores propios de una dama decimonónica cristiana, muere maldiciendo al cruel europeo.

\section{Conclusiones}

La consideración de estas tres composiciones nos permite señalar que el poema épico Argentina y conquista del Río de la Plata es su hipotexto y, por ello, un documento de función significadora en la cultura rioplatense. Así, uno de los ejes que permitió el desarrollo expresivo de la realidad americana y la tradición local fue la recepción del poema del arcediano. A partir de él, comienza a trazarse lo que Teresa Porzecanski (2000) denomina «mitología de la ausencia» (55) en relación a las colectividades charrúa, guaraní y aborigen en general, en los discursos modelizadores de la ficción porteña y oriental.

Desde el punto de vista de un sistema en común, con las variantes ideológicas y las diversas acciones militares sobre los pueblos originarios (la matanza de Salsipuedes de 1831 y la Campaña del Desierto y sus antecedentes argentinos), éstos y otros autores demostraron un interés de reescritura sumamente innovador. En su caso, Gutiérrez completa su mirada con la labor de investigación histórica sobre las mitologías, las costumbres y el nivel cultural de varias naciones aborígenes, en las que refuta lugares comunes aceptados en su época. Por su parte, Berro se presenta como el iniciador de una temática que tiene tres representaciones posteriores.

Hay, en estas composiciones líricas del primer romanticismo rioplatense, una combinación de elementos muy sugerentes que supera la mirada ingenua hacia el pasado y el amor por la leyenda y la tradición de un grupo de poetas filorománticos. Al leer y reescribir el poema de Centenera, hay una decisión de 
trabajar sobre los aspectos lejanos, desconocidos y conscientemente negados del proyecto civilizador y europeísta del pensamiento liberal. Otros intereses convivían con las hordas salvajes de Echeverría y la mirada despectiva de otros contemporáneos sobre el elemento indígena. El tema del aborigen en la cultura criolla ha tenido un espacio escaso y significativo que habría que entender como una tendencia y no como fenómenos aislados.

Por último, queda la pregunta por la autenticidad cultural de estas leyendas y por la existencia de su cercanía con algún sustrato mítico guaraní y charrúa; una labor que seguramente hará aportes a la cuestión de la transculturación en este sistema literario.

\section{Bibliografía}

Bauzá, F. (1953): Estudios literarios. Montevideo: Biblioteca Artigas.

Berro, A. (1864): Poesías de Adolfo Berro, Andrés Lamas (ed.). Montevideo: Imprenta tipográfica a vapor.

Brothertson, G. (2010): «La América de Rodó: sus banderas y sus silencios». En Centro Virtual Cervantes: http://bib.cervantesvirtual.com/FichaObra. html? Ref=35150\&portal=351 (29-07-2014).

Gutiérrez, J. M. (1869): Poesías. Buenos Aires: Imprenta y Librería de Mayo.

Gutiérrez, J. M. (1940): Críticas y narraciones. Buenos Aires: Jackson (Grandes escritores argentinos, 22).

Gutiérrez, J. M. (1940): Escritos bistóricos y literarios. Buenos Aires: Jackson (Grandes escritores argentinos, 48).

Díaz-Caballero, J. (2005): «El incaísmo como primera ficción orientadora en la formación de la nación criolla en las Provincias Unidas del Río de la Plata». En: A contracorriente, $3, \mathrm{n}^{\circ} 1,67-113$.

Frazer, Sir J. (1981): La rama dorada. Magia y religión. México: Fondo de Cultura Económica (trad. E. y T. Campuzano).

González Stephan, B.; Lasarte, J.; Montaldo, G.; Daroqui, M. J. (Comps.) (1995): Esplendores y miserias del siglo XIX. Cultura y sociedad en América Latina. Caracas: Monte Ávila Editores.

Guérin, M. (1990): «Discurso histórico y discurso ficcional en La Argentina de Ruy Díaz de Guzmán», Revista Río de la Plata, 11/12, 67-75.

Lojo, M. R. (2007): «Introducción». En: Mansilla, E., Lucía Miranda. Madrid/ Frankfurt: Iberoamericana/Vervuert, 11-137. 
Meléndez, C. (1961): La novela indianista en Hispanoamérica, 1832-1889. Río Piedras: Universidad de Puerto Rico.

Ortiz Gambetta, E. (2007): «Juan M. Gutiérrez y la recepción de la literatura española en la generación argentina de 1837». En: Trujillo Maza, Ma. C. (Dir.), Lectores, editores y audiencia. La recepción en la literatura bispánica. Barcelona/Vigo: ALEPH/Universidad Autónoma de Barcelona/Academia del Hispanismo, 433-438.

Ortiz Gambetta, E. (2013): Modelos de civilización en la novela de la Organización Nacional (1850-1880). Buenos Aires: Corregidor.

Pas, H. (2012): «¿Ecos de Lautaro? Las lenguas indígenas como patrimonio cultural del nacionalismo criollos en el siglo XIX». En: Anclajes, diciembre, 73-92.

Pelliza de Sagasta, J. (1877): "La chiriguana". En: Novelas americanas. Regalo de La ondina de Plata a sus suscriptores de 1877. Buenos Aires: Imprenta y Administración La Ondina del Plata, 7-32.

Porzecanski, T. (2000): «Indios, africanos e inmigrantes europeos: la búsqueda del origen en los nuevos discursos del imaginario uruguayo». En: Catálogo de la exposición “Como el uruguay no bay”. Montevideo: MMJMB, 84-100.

Rosenblat, A. (1964): El nombre de la Argentina. Buenos Aires: Eudeba.

Rama, A. (1968): Historia ilustrada de la civilización uruguaya, vol II. Montevideo: Arca.

Real de Azúa, C. (1968): «Los clasicistas y los románticos». En: Capitulo Oriental. La bistoria de la literatura uruguaya. Desde los orígenes al novecientos. Montevideo: CEDAL.

Roxlo, C. (1912): Historia crítica de la literatura uruguaya. Montevideo: Barreiro y Ramos.

Rodó, J. E. (1965): “Juan María Gutiérrez y su época”. En: El mirador de Próspero. Montevideo: Biblioteca Artigas (Colección de clásicos uruguayos, 30- II), 229-335.

Salto, G. (2010): "Somos un pueblo sin recuerdos. Las propuestas de independencia literaria”, En: Pilquen, 12: 1-9.

Santiago, R. de, (s/f.): “Cabarî" (transcripción paleográfica de Alejandro Gortázar): http://www.fhuce.edu.uy/index.php/letras/seccion-de-archivo archivo-y-documentacion-del-instituto-de-letras/acervo-documental/ miscelaneas/582-santiago-ramon-de (29-07-2013). 
Zorrilla de San Martín, J. (1943): "Índice alfabético de algunas voces indígenas empleadas en el texto”. En: Tabaré. Leyenda patria. Montevideo: Claudio García, 247-259.

Zum Felde, A. (1985): Proceso intelectual del Uruguay. Del coloniaje al romanticismo. Montevideo: Librosur, 111-146. 
Eugenia Ortiz Gambetta

National University of La Plata

\section{Native Legends in Juan María Gutiérrez and Adolfo Berro's Poetry}

Keywords: Adolfo Berro, Juan M. Gutiérrez, native legends, ethnography, literature.

This paper aims to consider how Caicobé and Liropeya's legends had fictionalized in Adolfo Berro's "Yandubayú y Liropeya (año de 1574)" (1840) and Juan M. Gutiérrez's "Caicobé" and "Irupeya" (1843). These pieces are linked to other poems, plays and novels from Argentina and Uruguay. All of its was based on the work Argentina y conquista del Río de la Plata (1602) by M. del Barco Centenera and use its ethnographic topics to construct the River Plate identity. These works make up the imagery of the "mythology of absence" in relation to the Charruas and Guarani people, modeller speeches of Buenos Aires and oriental fiction. 
Eugenia Ortiz Gambetta

Državna univerza v La Plati

\section{Staroselske legende v liriki Juana M. Gutiérreza in Adolfa Berra}

Ključne besede: Adolfo Berro, Juan María Gutiérrez, staroselske legende, etnografija, književnost

Glavni namen prispevka je predstaviti povezavo med predelavami zgodbe o Caicobéju in Liropeyi v pesmi Adolfa Berra Yandubayú y Liropeya (año de 1574) (1840) ter pesmih Caicobé in Irupeya (1843) Juana M. Gutiérreza. Ta besedila so tesno povezana $z$ drugimi urugvajskimi in argentinskimi deli 19. stoletja, ki bodo upoštevana pri analizi, toda največ pozornosti bo namenjene pesnitvi Argentina (1602) arhidiakona Martína del Barca Centenera, saj gre za hipotekst in glavni etnografski vir. V izoblikovanju argentinske in urugvajske literarne tradicije ta dela predstavljajo imaginarij »mitologije odsotnosti« za ljudstva Charrúa, Guaraní in staroselske skupnosti nasploh. 